germinates better and produces more vigorous plants. Schubert (East Germany), working with seeds of Robina pseudacacia on the thorny problem of seed quality evaluation, found that dehydrogenase activity, indicated by the change of colourless triphenyl tetrazolium chloride into bright red formazan, is indeed a reliable index of the viability and vitality of seeds, provided pre-soaking and treatment are effectively standardized and the results receive expert interpretation. To verify his conclusions from the tetrazolium (TTC) test, Schubert has developed a non-lethal TTC treatment $(0.01$ per cent for $24 \mathrm{~h})$, which permits normal germination and seedling growth. One disadvantage of TTC is its failure to record heat damage to tissues. Lindner (East Germany) demonstrated a similar inability of TTC to differentiate between normal seeds and those which have been damaged by excessive levels of mercury fungicides. In an attempt to forecast the performance of seeds in the field (their 'vigour') Lindner had found that with many farm and garden seeds, notably cereals, the upright-rolled-paper (Keimrollen) test provides much more information than other tests about the quality of consignments of seeds, since seeds which germinate but weakly can be clearly observed.

A number of speakers dealt with the modification of plant performance through the manipulation of germinating seeds. Krekule (Czechoslovakia) pointed out the importance of standardizing both the stage of germination reached and the water content of the seed at the time when vernalization is applied: a close correlation between the growth made before, and the result achieved by, vernalization exists only within narrow limits, outside which the results may be erratic. In a fascinating review, Henkel (U.S.S.R.) dealt with the utilization of what he called the 'plasticity' of plant material: for example, re-imposition of drought on imbibed seeds of many species increases the viscosity and elasticity of their protoplasm, enabling the resulting plants to withstand drought or heat later in life better than would unprepared plants.

Several papers dealt with the germination of bacterial spores. Lund and Norris (Great Britain) investigated the enzyme and antigen changes during germination of $B$. cereus spores using starch-gel and immuno-electrophoresis. A paper by Vinter (Czechoslovakia) dealt with the characterization of the individual steps of the development of spores into vegetative structures, and Mach (East Germany) reported on the ultra-structure of germinating Streptomyces spores.

There is little doubt that the Proceedings of this fertile symposium, to be edited by Prof. Borriss and published by Gustav Fischer, Jena, will be consulted for many years to come. Here are shown not only the complexity and the specificity but also the recurring patterns, which have been uncovered in the processes that occur during the vital transition from dormancy to growth.

It remains to be hoped that the international exchange of ideas which was made possible at Greifswald by personal contact will continue, irrespective of political frontiers.
W. HeYDECKER

\title{
PHARMACOLOGY AND THERAPEUTICS IN PAKISTAN
}

$\mathrm{T}$ HE Pakistan Society of Pharmacology and Therapeutics, which was formed on July 14, 1962, was officially inaugurated on March 20, 1963, at Lahore by Dr. Salimuzzaman Siddiqui, chairman of the Pakistan Council of Scientific and Industrial Research. The inauguration was held during the fifteenth All-Pakistan Science Conference with the necessary assistance of the Pakistan Association for the Advancement of Science. Dr. S. M. K. Wasti (Lahore), who was appointed as the organizing secretary by the Pakistan Association for the Advancement of Science, acted as a liaison officer between the Society and the Pakistan Association for the Advancement of Science. The help from the Departments of Health of the Government of Pakistan and of the Governments of the East and West Provinces, which enabled all the professors of pharmacology in Pakistan to attend the inauguration, needs a special mention.

The inauguration ceremony opened with a recitation from the Quran. Prof. A. Hameed Khan (Lahore), chairman of the reception committee, welcomed the participants and pointed out that the rapid growth of pharmacology needed a high standard of education and training in that science. He also emphasized the importance of pharmacologists in the drug industry and of the need for a fully equipped and properly staffed laboratory for drug testing, including facilities for the biological standardization of products manufactured in Pakistan. Prof. S. M. A. Zaidi (Hyderabad), general secretary, in his introduction, mentioned the various important objectives of the Society which included an improvement in the teaching of the subject in order to make drug therapy absolutely safe in the hands of medical practitioners. He also referred to the proposed role of the Society in promoting research, specially on the indigenous plants of medicinal value. Prof. Zaidi also outlined the part which the Society could play in the compilation of a National Pharmacopoia for Pakistan.

In his presidential address Dr. Siddiqui said that scarcely 2 per cent of the 191,000 species of flowering plants had been examined for alkaloids. He appealed to all the pharmacologists in Pakistan to devote their efforts to the investigation of the medicinal plant wealth of the country, with the view of developing new therapeutic agents for the treatment of human ailments on a scientific basis. Referring to pharmacological research on the medicinal plants, Dr. Siddiqui concluded his address by saying, "It is, indeed, a truly virgin field of seientific and economic endeavour, and it shall be my hope that your Society will in all earnestness accept the challenge and the opportunity it offers".

The inaugural address was followed by the presidential address, which was given by Prof. Nazeeruddin Ahmed (Multan). In his address, Prof. Nazeer criticized the teaching of pharmacology as recommended by the Medical Reforms Commission. He said that "the report of the Medical Reforms Commission has forcibly put the pharmacological cart before the physiological horse. This anomalous situation has added greatly to the burden of the teachers and the taught because the fabric of pharmacology normally rests on the foundation of physiology". Prof. Nazeer mentioned a number of useful purposes which the pharmacologists and the teaching departments of pharmacology in Pakistan could solve, for example, standardization of drugs, training of dispensers, ete. Later, Mr. A. Campbell Benzie (Burroughs Wellcome and Co.) read out the messages of goodwill received from both Pakistan and abroad. Prof. M. Rabbani (Lahore), who is Pakistan's most senior pharmacologist, described the formation of the Society as a great step in the scientific progress of the country and congratulated the pioneers. He thanked the delegates and other participants and the organizers of the inaugural function.

At the symposium on "Pharmacology" which followed, a number of papers on various aspects of the subject were read. The opening paper, "The Scope of Research in Pharmacology in Pakistan", was given by Prof. Mir Mansur Ally (Dacca), who, besides elucidating the importance of the natural drug resources, pointed out the 
important handicaps of the research workers, their inadequate pay, poor status and lack of facilities. He also advocated a free access of the pharmacologists to the hospital wards for therapeutic problems. Prof. Inayat Khan (Karachi) discussed the role of a pharmacologist in the pharmaceutical industry of Pakistan. In collaboration with Dr. Siraj Ahmed (Peshawar), he communicated the answers to a questionnaire on the subject sent to various persons connected with the industry and the science. The conclusion drawn from this survey was that there was considerable justification for pharmacologists being included on the staff of the pharmaceutical industry of Pakistan.

The remaining papers were concerned with the teaching of pharmacology. Dr. S. A. Wahid Shah (Peshawar) spoke on "The Teaching of Pharmacology in the Laboratory". He emphasized the importance of students conducting their own experimental work as an aid to grasping the subject more intelligently. He quoted a number of such experiments which could supplement the formal lectures. Dr. M. Shamsuzzoha (Chittagong), while discussing the teaching of pharmacology, eriticized the place of the subject in the medical curriculum as a result of the report of the Medical Reforms Commission. He considered that it was not possible for a student to grasp the subject without having an understanding of the fundamentals of physiology, and that teaching drug actions without their application would have an adverse offect on known and accepted teaching methods. Prof. S. M. A. Zaidi (Hyderabad) said that the views of those who taught represented only one side of the story and that it was necessary also to consider the reactions of those who are taught. Prof. Zaidi communicated the results based on the answers received from medical students and general medical practitioners in response to a questionnaire prepared by him. The conclusion was that the subject should be taught after a student had gained a basic knowledge of physiology, biochemistry, pathology and microbiology, and that it should be taught in an applied manner throughout the clinical period. Dr. Anis Mahju (Karachi), while giving his views on postgraduate education in pharmacology, was of the opinion that a student must be encouraged to develop the habit of self-education. He described the programme which a student had to follow at the Postgraduate Medical Centre, Karachi. $\mathrm{He}$ also emphasized the importance of frequent seminars and group discussions in which a student could freely participate.

Due to the shortage of time, the papers on the National Pharmacopceia by Prof. M. Rabbani (Lahore) and on the scope of research in pharmacology by Dr. K. Ahmed (Rajshahi) could not be read. These will appear in the Proceedings of the symposium.

The afternoon session was devoted to the scientific papers, including: "Synergistic Action of Serpajmaline and Isochaksine" by Dr. S. Siddiqui and Prof. M. M. Ally; "Pharmacological Investigations of Harmidine" by Prof. A. H. Khan and Dr. M. Cheema; "Some Aspects of the Influence of $p \mathrm{H}$ on Drug Action" by Dr. M. Shamsuzzoha; "Effect of Nilamide and Certain Arteriosclerotic Agents on Blood Platelets and Blood Coagulation" by Dr. A. Mahju, and "Micro-biological Assay in Drug Standardiza- tion" by Dr. M. W. Ali and Dr. R. A. Khan. There were a number of other research papers connected with pharmacology which could not be read due to a shortage of time.

On the following day a general meeting of the Society was presided over by Prof. Nazeeruddin Ahmed. The following decisions were made:

(1) That a uniformity should be aimed at in the curriculum and examinations in the subject of pharmacology, including therapeutics, in all the medical colleges in Pakistan.

(2) That there should be a uniformity in the staff strength in departments of pharmacology throughout Pakistan, and that there should be a parity in the salaries of teachers in the medical colleges of both parts of the country.

(3) That attempts should be made to start courses for the B. Pharmacy degree in all medical colleges in Pakistan, in order to meet the demands of the rapidly expanding pharmaceutical industry.

(4) That a quarterly journal, to be named the Pakistan Journal of Pharmacology and Therapeutics, should be started as soon as possible. (It was decided that the chairman of the publication sub-committee should act as chief editor, and should be left to constitute his own sub-committee for the publication of that journal.)

(5) That a sub-committee should be formed to expedite the publication of a text-book on pharmacology suited to the needs of students in Pakistan, consisting of Prof. Mazharul Haq (Karachi), Prof. S. M. A. Zaidi (Hyderabad) and Prof. Inayat Khan (Karachi).

(6) That lectures and discussions, aimed at benefiting the general medical practitioners, should be arranged by the various departments of pharmacology in collaboration with the Pakistan Medical Association.

(7) That the research sub-committee of the Society should compile a list of the problems under investigation in various departments and invite schemes for further research work. The sub-committee should also find ways and means of developing, co-ordinating and financing the various research schemes.

(8) That a sub-committee should formulate the basic principles, for submission to the Government, which should be kept in view at the time of compiling the National Pharmacopoeia and that this sub-committee should participate in the deliberations of various committees which may be appointed by the Government for the said purpose. The committe would consist of Prof. Mazharul Haq (Karachi), Prof. S. M. A. Zaidi (Hyderabad), Prof. Inayat Khan (Karachi), and Dr. M. Shamsuzzoha (Chittagong).

(9) That the next annual general meeting should be held at Layallpur at the time of the next Science Conference.

(10) That the Medical Council, which is the body controlling medical education in Pakistan, should have representatives of all the subjects in the medical curriculum on its panel and that a pharmacologist should be taken on immediately.

(11) That the word "Experimental" be dropped from the name of the Society and that it be called the Pakistan Society of Pharmacology and Therapeuties.

\section{S. M. A. ZAIDI}

\section{RECURRENT 'STOMACH ACHE'}

\begin{abstract}
HE Glaxo Volume is published occasionally as a contribution to the science and art of medicine. Among the interesting articles in the twenty-seventh issue is one dealing with recurrent 'stomach ache'. Abdominal pain which recurs at intervals seems to affect
\end{abstract}

children everywhere throughout the world. In England the frequency of the complaint has been estimated from a survey of schoolchildren. This showed that, among 1,000 unselected children, more than 1 in 10 had had at least three attacks of abdominal pain and some had had 